\title{
RISK COMMUNICATION IN ORDER TO FACILITATE COMMUNITY RESILIENCE AGAINST A LARGE-SCALE FLOOD
}

\author{
TAKEYASU SUZUKI \\ Disaster and Environmentally Sustainable Administration Research Center, University of Yamanashi, Japan
}

\begin{abstract}
Due to global abnormal weather, large-scale floods that exceed the planned scale flood have occurred in Japan in recent years. The necessity of wide-area evacuation beyond municipal boundaries is required in order to prevent further victims, because drowning and isolation occurred due to recent large-scale floods. The author applied the risk communication method proposed by the author to the Riverside District (about 1,400 households with a population of about 4,000), Chuo City, Yamanashi Prefecture, Japan which is close to the river bank of the large river and is one of the most dangerous districts out of the inundation area of the Kofu Basin. The northern half of the district is in the zone where houses are swept away by streams of water when bank breakage occurs. The risk communication was designed by setting implementation items at each of five processes "C-A-U-S-E", incorporating workshops, questionnaire surveys or presenting evacuation simulation results. Through three years of risk communication activities, local residents were aware of and understood the flood risk which exists in the community, found a solution on its own, accepted proposals for wide-area evacuation, and finally they formulated the community disaster management plan for the wide-area evacuation. This paper introduces all processes of this risk communication and endogenous activities by the residents and systematically summarizes achievements as the risk communication method.

Keywords: risk communication, community resilience, community disaster management plan widearea evacuation, flood.
\end{abstract}

\section{INTRODUCTION}

The number of typhoons frequenting Japan, including the amount of precipitation, has appeared to increase in recent years because of the global weather anomaly [1]. Moreover, whereas both the national and local governments have strengthened and implemented strict laws on disaster mitigation, preparedness and response, people's awareness of self-help and mutual help during a disaster has weakened, thereby raising the tendency to rely on administrative aid for disaster management [2]. Imminent dangers associated with a typhoon landing, such as river flooding, sediment disasters, and tsunamis, could be avoided through strategic evacuation management planning and implementation.

This highlight of this study is dealing with the impact of a large-scale flood scenario. In 1959, approximately 5,098 human casualties, the largest in Japan's history on typhoon damage, were recorded on the landing of the Isewan Typhoon. In turn, the typhoon impact paved a way for the introduction of several countermeasures, including the Disaster Countermeasure Basic Act, the River Act, and the Flood Control Act, among others. Following their successful implementation, which resulted in a reduction in the number of human casualties in recent years, these countermeasures have been continuously developed and improved up to the present time. In line with an earlier premise, the scale of the damage caused by flooding due to heavy rainfall has likewise widened, to the extent that floods induced by mountain rivers (which normally contain debris and sediment) have seemingly become frequent. From an environmental perspective, disasters are also triggered by harmful activities or a predisposition against nature and society, normally by us. 
The heavy rains experienced today tend to surpass both the structural and non-structural countermeasures, with the accompanying fear that the extent of this damage will only intensify in future. Structural measures are indispensable, yet they require a great deal of time to develop. On the other hand, non-structural measures, such as people's awareness of disaster management, are easy to establish, but nonetheless require strengthening and improvement. At present (i) realization of an early warning system for incoming disasters and (ii) evacuation schemes are urgent demands.

\section{CURRENT STATUS OF WIDE-AREA EVACUATION}

The 2015 Kanto and Tohoku heavy rains resulted in massive flooding of the Kinugawa River and $40 \mathrm{~km}^{2}$ or one-third of the area of Joso City in Ibaraki Prefecture, leaving two human casualties. At the height of the flood, more than 4,000 people were stranded in the flooded area and later rescued by helicopters and boats [3]. A survey conducted by Irie [4] indicated that the largest number of evacuees, accounting for $35 \%$ of the total, was headed outside Joso City via car transport ( $89 \%$ of all related evacuation means). In terms of motive, $41 \%$ of the evacuees were "family and friends prompted". Moreover, most of those affected indicated that their reason to remain indoors was to maintain a semblance of normality, believing that the heavy rain would not inundate, or that it was difficult to move "considering the elderly". The reason "neighbors are not evacuating" rated high as well, accounting for $12 \%$ of the survey responses.

The July 2018 Western Japan heavy rain disaster caused the Oda River, Suematsu River, and Takama River to overflow in Mabi-cho, Kurashiki City, Okayama Prefecture. Approximately $27 \%$ or $27 \mathrm{~km}^{2}$ of Mabi-cho, was flooded leaving 51 human casualties, of which 45 (88\%) were elderly (over 65 years of age) [5]. At least 42 people needed evacuation aid. The evacuation rate during floods in Japan has not yet reached $10 \%$. This implies that during large-scale floods, those who cannot evacuate by themselves become casualties.

Typically, such large-scale flooding causes houses to collapse and other properties or structures to get washed away from break points of rivers. Evacuation should not only be judged by the depth of inundation but also by the presence of a dike nearby, where banks may break and intensify water flow. Fig. 1(a) shows the damage near the break point of Joso City during the 2015 Kanto Tohoku heavy rainfall. Similarly, Fig. 1(b) illustrates the extent of damage caused by the 2018 Western Japan heavy rainfall in Mabi-cho.

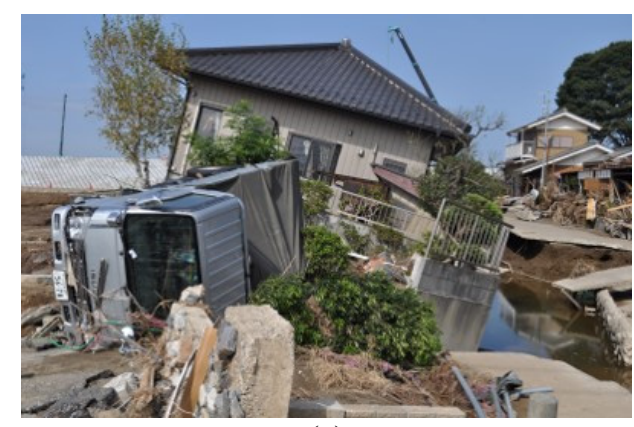

(a)

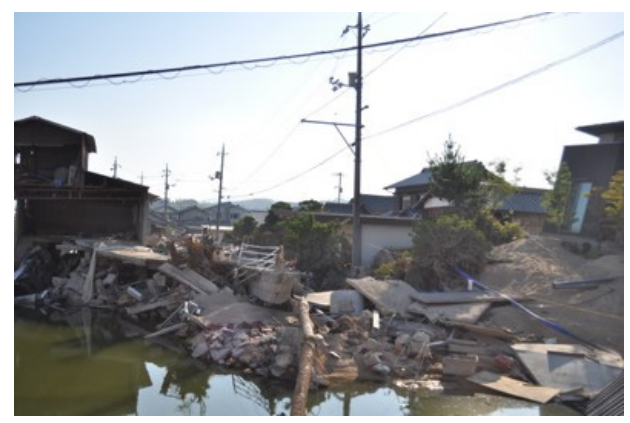

(b)

Figure 1: Damage to houses and properties near river banks or break points caused by large-scale flooding. (a) Joso City at the height of the 2015 Kanto Tohoku heavy rain disaster; and (b) Mabi-cho, Kurashiki City during the 2018 Western Japan heavy rain disaster. 
As mentioned earlier, a wide-area scheme is necessary to incorporate early evacuation outside the municipalities before the incoming disaster, based on lessons learned from the flooding in Joso City and Mabi-cho. Such a scheme should prioritize those needing immediate evacuation, with transportation readied by local municipalities toward welfare facilities coupled with the support of neighbouring communities [6]. In other words, coordination between residents and governments is an essential element in the evacuation scheme. Moreover, a wide-area evacuation of community residents can be realized, provided they willingly intend to evacuate. Such intentions can be strengthened by a platform encouraging residents to evacuate through the support of families, friends, and neighbours, and the local government will provide control and guidance in terms of transport and safe routes. In addition, the success of evacuation is dictated by the strength of coordination and communication between municipalities, especially when transferring evacuees to public shelters or welfare facilities [6].

The present study has developed a risk communication method mainly characterized by the CAUSE, for training on the creation of a disaster prevention system for local governments and community residents [8]. This study has also conducted demonstrative research. The focal objectives herein are basically aligned with introducing efforts on risk communication implemented in recent years for the wide-area evacuation of people from the Kofu Basin in case of an expected maximum flood level.

\section{FLOOD RISK IN THE KOFU BASIN}

Residents who do not evacuate even when normal evacuation information is issued will impede the success of a well-organized wide-area evacuation scheme. A wide-area evacuation plan is defined as a strategy that spans several municipalities and is organized by prefectures. Nevertheless, scheme proposals from both prefectural and municipal governments will not be readily accepted by community residents unless residents are convinced of the necessity to evacuate. As such, a more efficient community disaster management plan on wide-area evacuation could be formulated by considering the proactive activities of the residents, so that the intent of municipality support as well as the coordination scheme between municipalities, prefectures, and residents can be clarified. This study asserts that an effective formula should be created in a bottom-up structure, where community residents play an active role in establishing evacuation plans.

Fig. 2 shows the location of the Kofu Basin in Yamanashi Prefecture. The Eurasian Plate and the North American Plate collide in the east and west respectively, and the highest mountain range in Japan is formed to the west of the basin. Meanwhile, the Philippine Sea Plate collides with the two plates from the south, and subducts under the Eurasian Plate and the North American Plate. The Kofu Basin is located at the collision center of the three plates and has a mysterious structure with an inverted triangle. Additionally, it is located in the Mt. Fuji volcanic belt, with Mt. Fuji to its south. Aesthetically, it is surrounded by beautiful mountain greenery and hot springs. However, the collapsed earth located in the north of the basin due to volcanic activities is deeply deposited in the subsurface of the basin. On the basin perimeter, fans are formed by the supply of debris flow deposits from mountainous rivers. During heavy rainfall, sediment and water from the surrounding mountains gather in the basin. Particularly because rivers drain flood water to the center of the basin, crops in the land could not be harvested. Since the Middle Ages, dikes have been purposely constructed and flood control schemes have been implemented to move the river channel to the edge of the basin, in an effort to turn the land into a suitable area for crop cultivation. 


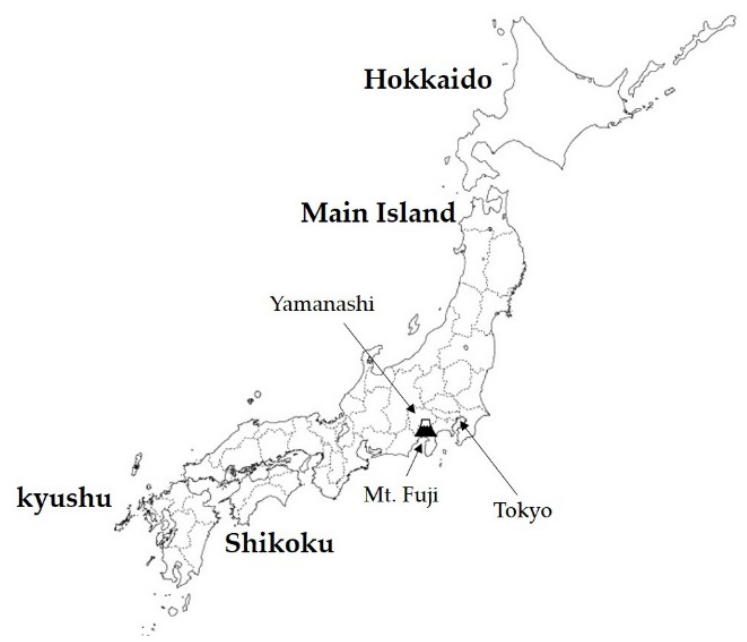

Figure 2: Japanese Archipelago and location of Yamanashi Prefecture.

Fig. 3 shows the main rivers and possible inundation on the Kofu Basin. The inundation area, due to expected maximum rainfall (a probability of 1 in every 1,000 years), is demonstrated on the hazard map according to the categorization of the Ministry of Land, Infrastructure, Transport, and Tourism (MLIT), and the inundation area of Mabi-cho, Kurashiki City, Okayama is also shown on the same scale. In comparison, Kofu Basin has a larger inundation area (specifically, more than 10 times larger than that of Mabi-cho), which indicates that the evacuation distance exceeds $10 \mathrm{~km}$, depending on the location in the basin; therefore, evacuation by car is more suitable. For example, out of a total population of 22,000 people, 51 died during the July 2018 heavy rainfall in Mabi-cho, representing a mortality rate of $0.23 \%$. If such a rate is applied to the inundation area in the Kofu Basin with approximately 300,000 people, the death toll would be an estimate of 690 . However, given the low evacuation rate performance of Yamanashi Prefecture in recent years, this figure is underrepresented.

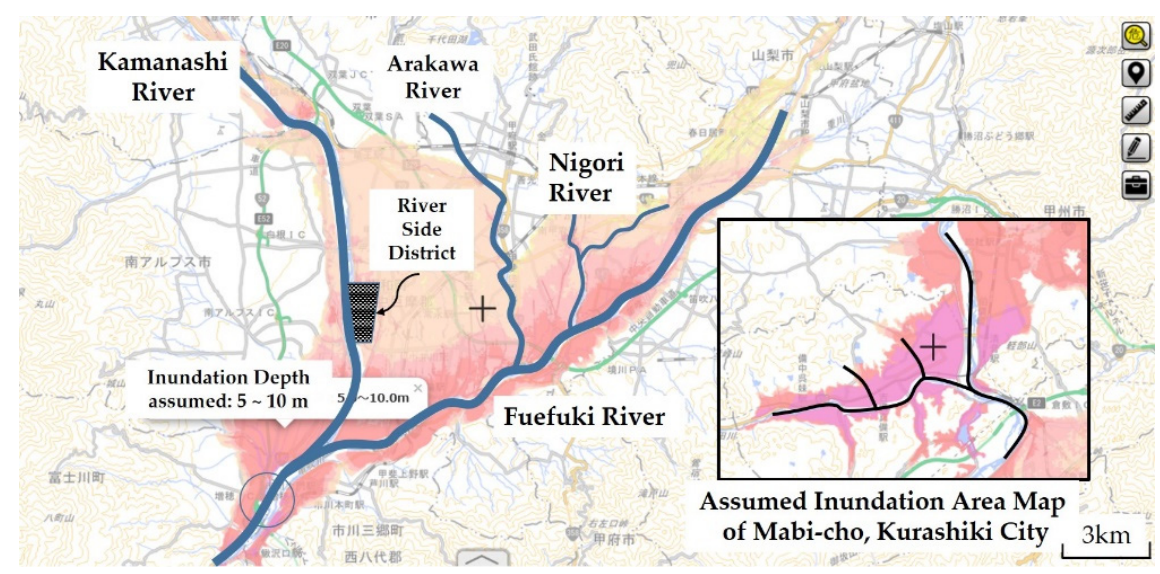

Figure 3: Assumed inundation map of the Kofu Basin compared with that of Mabi-cho. 


\section{FACILITATING COMMUNITY DISASTER MANAGEMENT PLAN}

\subsection{CAUSE model}

The CAUSE model was proposed by Rowan as a risk communication method aimed at educating regional crisis managers [7]. CAUSE literally represents Confidence, Awareness, Understanding, Satisfaction with the proposed solution, and Enactment, which are also the essential stages of risk communication. Here, the crisis manager is assumed to be in an administrative job, such as a police officer or a fireman, whose communication counterpart is the general population. That is, crisis managers need to learn what people do at each stage of the CAUSE model to provide them with risk awareness, understand their content, accept the solutions presented by the risk managers, and put them into action.

Although the CAUSE model proposed by Rowan is an educational process for local crisis managers to communicate with the general population, the CAUSE model developed in this study is a risk communication method that improves the disaster response ability of the municipalities and the community resilience of the residents. Here, S (together with Satisfaction) includes the stage of the solution, where participants propose solutions or decide on solutions by themselves [8].

\subsection{Community disaster management plan}

Japan has established the Disaster Countermeasure Basic Act as a comprehensive and longterm plan at the national level and a regional disaster management plan for prefectural and municipal governments at the local level, and has implemented disaster management activities at each level.

However, in the 2011 Great East Japan earthquake, it was strongly recognized that disaster countermeasures after a large-scale wide-area disaster work well with the mutual cooperation of self-help, mutual help and public help. On the basis of the lessons learned, some provisions concerning self-help and mutual help were added in the Disaster Countermeasure Basic Act in 2013. At that time, from the point of view of the promotion of disaster management activity by mutual help in the local community, a community disaster management plan system regarding voluntary disaster management activities conducted by residents and businesses (community residents, etc.) of certain districts in municipalities was formulated.

\subsection{The first stage of risk communication}

The Riverside District in Fig. 3 is the name of a community indicating a so-called Riverside Town in Chuo City, Yamanashi Prefecture. It is located on the left bank of the Kamanashi River, and was once a water reservoir sandwiched between a dike and the left bank of Kamanashi River. The Usuinuma swamp was formed after the flood of the Kamanashi River in 1907. Reclamation of the swamp began in 1959, and residential area construction has been carried out as the largest residential district (a future population of 7,000) in the Kofu Basin. Nearly 1,400 households and 4,000 residents live in the area. Residential land started being sold from the north area, represented by three residents' associations: the 1st Association of the North, the 2nd Association of the Central, and the 3rd Association of the South.

In 2015, the author received a request from the 3rd Residential Association for risk communication, which has since been initiated to support the formulation of a wide-area evacuation plan with no casualties [9]. During the initial stage of "Awareness", a questionnaire survey on flood risk in the district was conducted (with an estimated recovery rate of $65 \%$ ) targeting approximately 1400 households in the entire Riverside District. The 
results of the survey were shown in Fig. 4(a) and (b). When asked if you are interested in the flood in Joso City, $88 \%$ of residents replied "have strong interest" or "somewhat interested" as shown Fig. 4(a)). Next, in response to the question of whether there is a high risk of suffering similar damage as Joso City in this district, more than half of the residents answered "extremely high" or "high" as shown in Fig. 4(b). Through the questionnaire survey, community residents were made aware of the commonness of damage caused by floods in this district and Joso City (Awareness).

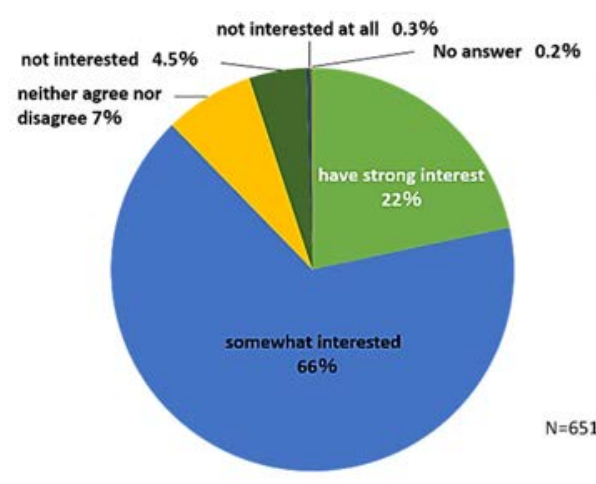

(a)

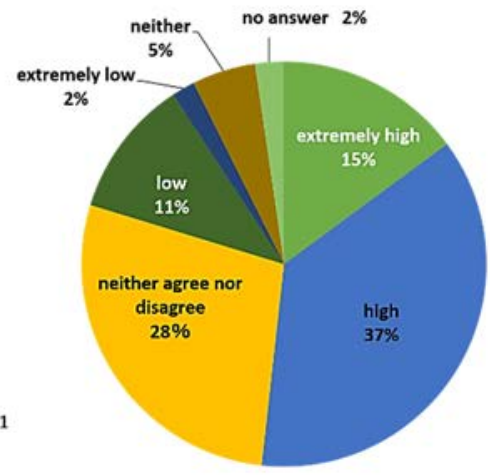

(b)

Figure 4: Results of questionnaire survey conducted at the stage of "Awareness".

In this questionnaire survey, some questions were asked about evacuation of persons who need help in evacuation. In response to the question of whether you know the persons who need help in evacuation living in the neighbourhood, the percentage of those who answered that they were grasping was 32\% at the 1st Residents' Association, $21 \%$ at the 2 nd Residents' Association, and $14 \%$ at the 3 rd Residents' Association, respectively. We asked the respondents who replied they were grasping what are the issues solved in the evacuation of persons who need help for wide-area evacuations. The answer to the question is summarized in Fig. 5. Thus, the residents are aware that means of transportation to shelters is the most important issue.

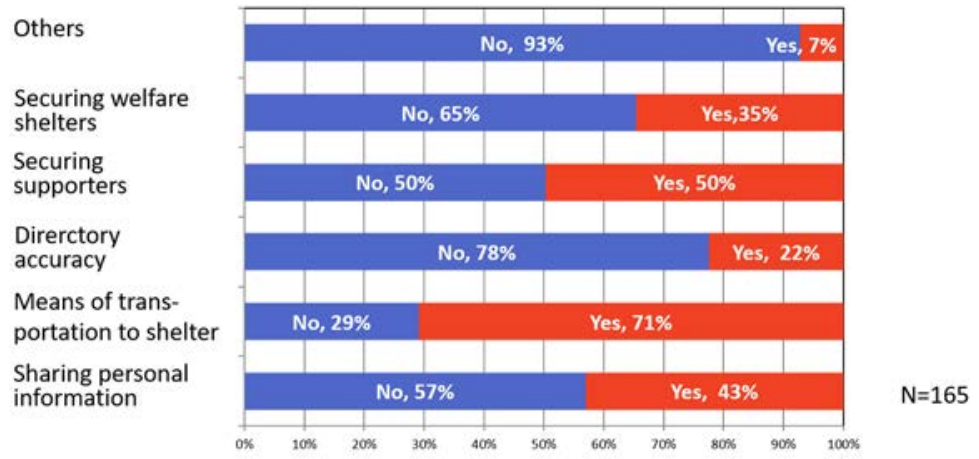

Figure 5: Summary of questionnaire survey on issues which should be solved in wide-area evacuation for persons who need help in evacuation. 
The next stage of "Understanding" was designed to promote understanding so that many district residents could participate in activities for evacuation of the area. Within the district, it will be necessary for community residents to mutually discuss wide-area evacuation and support to persons who need help each other in the neighbourhood. Therefore, the author thought that the distribution of the above-mentioned questionnaire results was effective. The results of the questionnaire survey are summarized as easy-to-understand reports such as adding large graphs, letters, and explanations of graphs. Based on this report, the author reported the results to the representatives of the three Residents' Associations and held a meeting to exchange views. As a result, the 3rd Residents' Association decided to copy the report by the number of households, and the chairman determined to explain to the group leaders in the leader meeting and to instruct the group leaders to inform all households of each group by the circulation board.

The report made the chairman of the 1st and 2nd Residents' Associations who had hesitated to start efforts to establish an evacuation support system for persons who need help. As a result, the report was to be informed in the same way at all of the 1st through 3rd Residents' Associations. The results of the questionnaire were shared with the many neighbouring residents, and it would provide a favourable environment for future efforts. Thus, residents shared the flood risk of the district and understood the necessity of an evacuation support system, especially for those needing help during evacuation (Understanding).

The author proposed the establishment of a system in which neighbours support those who need help for evacuation. The representatives of the 3rd Residents' Association agreed with the construction of the evacuation support system and asked the author for guidance on the specific construction method. Therefore, the author developed and proposed two types of assistance styles so that the supporter group can determine evacuation support activities as a timeline without a professional facilitator.

The first assistance style was used in order for supporters to grasp the required degree of support by asking the person who need help in evacuation about the communication ability and walking ability, and whether family support can be given. The next assistance style was used to summarize the role of each supporter as a timeline in the process of taking the person who need help to a temporary evacuation site. The 3rd Residents' Association accepted the method (Satisfaction), and a support system for six persons who need help for evacuation was immediately established. Fig. 6 shows the build-up of support system for the persons who need help for evacuation.

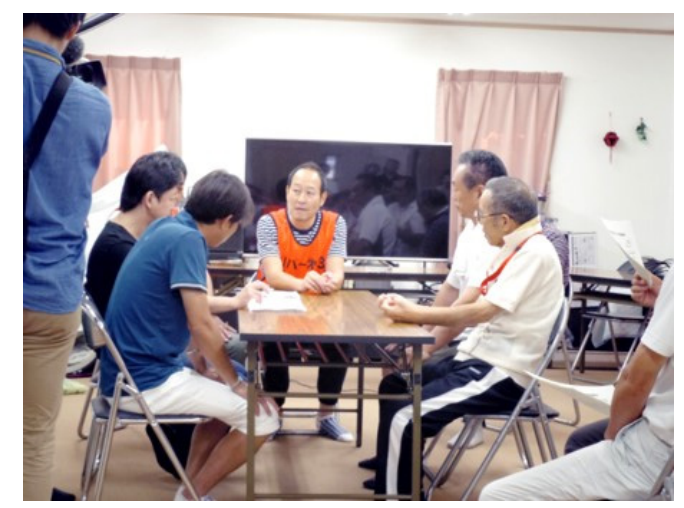

Figure 6: Build-up of support system for persons who need help for evacuation. 
Alternatively, district residents suggested that one should hang a towel on the second floor as a sign to inform completion of evacuation. It was decided to implement these suggestions and white towels were distributed to each household. (Satisfaction and Solution).

Therefore, a wide-area evacuation plan, in which all the district residents began evacuation outside the district after evacuating those needing help, was formulated by the 3rd Residents' Association in March, 2018 (Enactment) [9]. Subsequently, representatives of the 1st and 2nd Residents' Associations participated in this risk communication, learned, and joined the activities of the 3rd Residents' Association in the succeeding year.

\subsection{The second stage of risk communication}

In 2018, another process of the CAUSE model was applied to support the community disaster management plan of the entire Riverside District (from the 1st through the 3rd Residents' Associations). At the meeting of the representatives of the three residents' associations of the Riverside District held in August 2018, the author was informed that both the 1st and the 2nd Residents' Associations had finished establishing a support system for persons who need help in evacuation. At the meeting, the author introduced the results of the agent simulation of the evacuation from the district by car at the "Awareness" stage. In this simulation, the district was divided into a plurality of blocks in order to show the effectiveness of time difference evacuation in which time differences were made by giving an order for each block. When evacuations were started all at once, it was indicated that the intersection would become a bottleneck and traffic congestion would occur. Although some representatives stated that time difference evacuation was effective, some residents did not follow the rules of timed evacuation, and they said that they would start evacuation first.

Therefore, the author cut out screen shots near the bottleneck intersection from the evacuation simulation results, created the materials shown in Fig. 7 to explain the troubled situations that occur at various locations during simultaneous evacuation. As the stage of "Understanding", a questionnaire survey was conducted for all households in the district (using explanatory materials through screenshots of evacuation simulation by cars) to enable residents to understand the necessity of evacuation by cars, with a time difference in each block divided in the district.

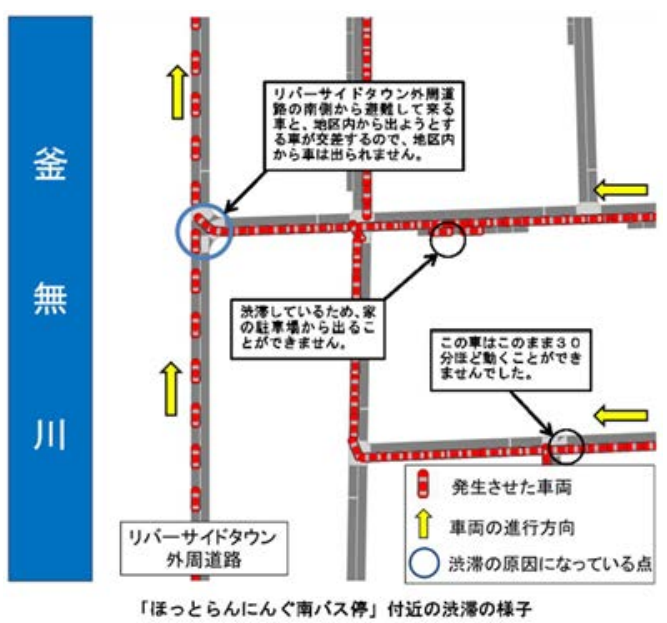

Figure 7: Explanatory material through screenshot of evacuation simulation. 
As a result, $91 \%$ of the answers from 557 people to the question of "what is the problem during evacuation with cars simultaneously?" was "the occurrence of traffic congestion". Apart from that, $47 \%$ of "restricted evacuation route" and $35 \%$ of "occurrence of traffic accident" were selected, so the district residents understood that traffic regulation was necessary. Fig. 8 shows the result of the answer to the question "Do you follow the instruction when the time difference evacuation instruction is issued from the residents' association?". The responses "follow" and "may follow" accounted for $65 \%$ and it was confirmed that the author's proposal on time-lag evacuation was accepted by many residents.

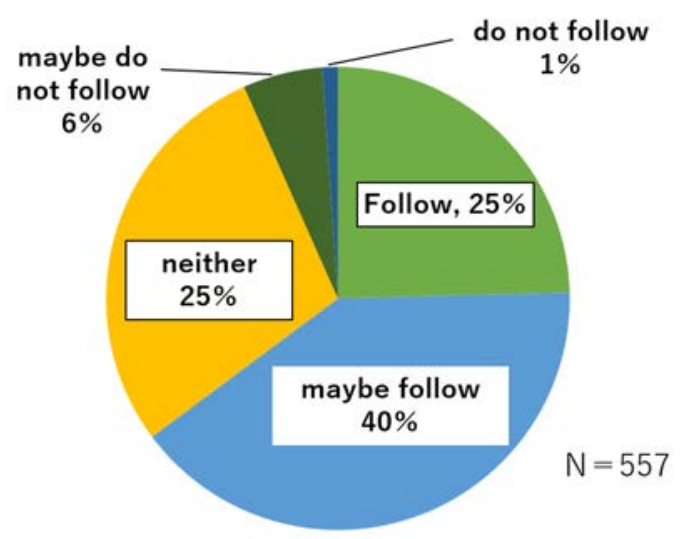

Figure 8: Result of the answer to the question "Do you follow the instruction when the time difference evacuation instruction is issued from the residents' association?".

In the Riverside District in Chuo City, Yamanashi Prefecture, the community disaster management plan for wide-area evacuation was formulated in the entire district in May 2019 (1,400 households of the 1 st to 3rd Residents' Associations with 4,000 people) at the final stage of "Enactment". Fig. 9 is a schematic representation of the wide-area evacuation plan for the Riverside District. Fig. 10 is the "My Timeline" of evacuation behaviour (and preparation) distributed to each household. When the authors presented such a timeline in the form of dividing the evacuation behaviour as shown in Fig. 10 into 10 stages, the residents added some ideas to finally create the timeline shown in Fig. 10. The timelines were printed on B5 size glossy paper in black and red two-colour printing and were distributed to all the households. According to the tabulation results, the recovery rate of collection slips was $65 \%$, where the timeline had already been created at $80 \%$. Thus, more than $52 \%$ of all households in the district were involved in the creation of the timelines.

\section{CONCLUDING REMARKS}

The author proposed the implementation of a risk communication approach by using the CAUSE model to evacuate community residents. In the Riverside District in Chuo City, the author proposed and implemented new processes based on the CAUSE model and implemented these twice for wide-area evacuation plan development. The first process covered the evacuation plan of the 3rd Residents' Association, and the second process expanded it to the entire Riverside District (1,400 households 4,000 people). As a result, the community disaster management plan of the whole district on the wide-area evacuation plan was formulated. 


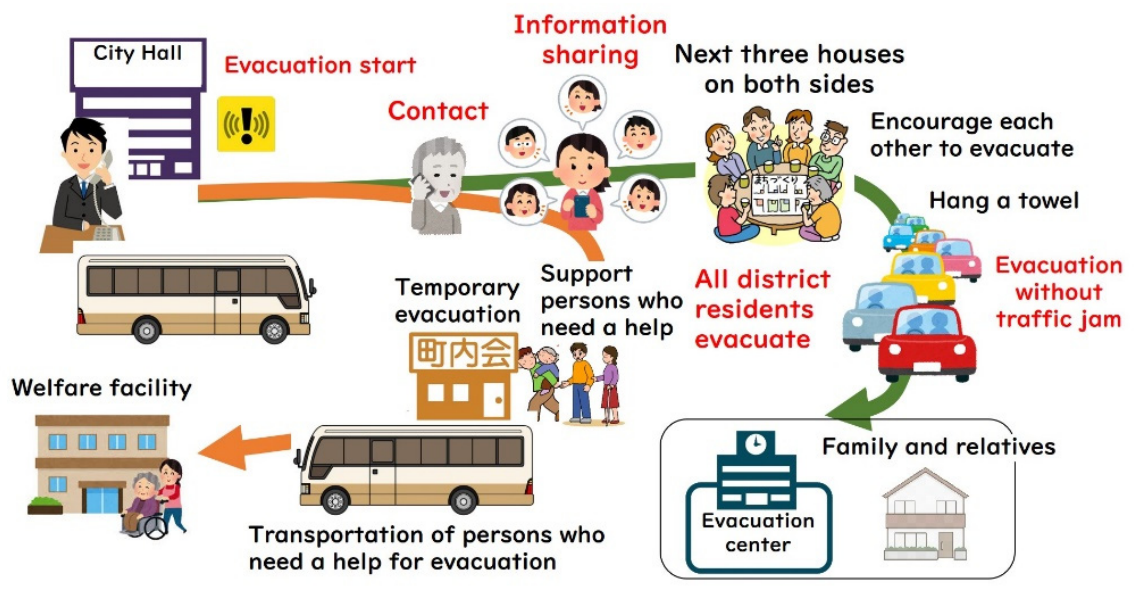

Figure 9: Schematic representation of the wide-area evacuation plan of Riverside District.

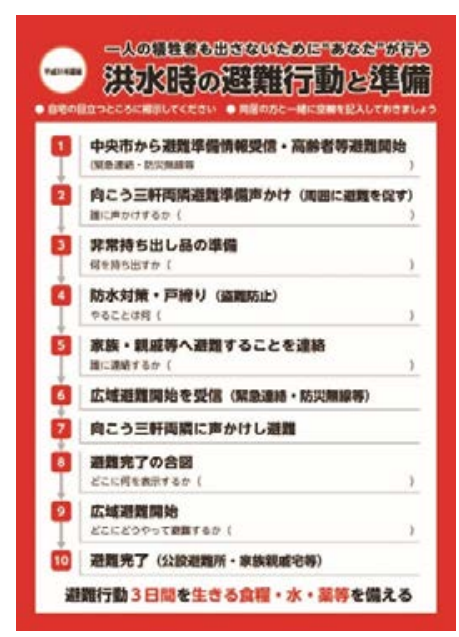

Figure 10: My Timeline for each household printed by Residents’ Associations.

Through three years of risk communication activities, local residents were aware of and understood the flood risk which exists in the community, found a solution on its own, accepted proposals for wide-area evacuation, and finally they formulated the community disaster management plan for the wide-area evacuation as an enactment.

\section{ACKNOWLEDGEMENTS}

The authors express their deep gratitude to the Ministry of Land, Infrastructure, Transport and Tourism and to the Kofu River National Highway Office for their funding and support of this research. Above all, the authors express their great appreciation to the residents of Riverside District for their cooperation in the questionnaire survey and in the creation of my timeline, and to the representatives of the district for distributing and retrieving the questionnaires. 


\section{REFERENCES}

[1] Cabinet Office of Japan, Disaster management in Japan. www.bousai.go.jp/1 info/pdf/ saigaipamphlet je.pdf. Accessed on: 10 May 2019.

[2] Murosaki, Y. \& Tominaga, Y., Chapter 5 Mutual Help in Creation of People to Confront Disasters, Minerva Shobo: Kyoto, Japan, pp. 77-86, 2018. (In Japanese.)

[3] Joso City Flood Control Verification Committee, Verification report on disaster response to flood in Joso City due to Kinugawa River flood, 2015. (In Japanese.)

[4] Irie, S., How did citizens in Joso City evacuate when the Kinugawa River broke down? Broadcast Research and Survey, pp. 36-65, 2016. (In Japanese.)

[5] Okayama Prefecture, Verification report on the July 2018 flood disaster: Verification committee of the July 2018 heavy rain disaster. www.pref.okayama.jp/uploaded/life/ 6017055031910 misc.pdf. Accessed on: 10 May 2019.

[6] Suzuki, T., System creation and information sharing environment aiming for wide-area cooperation at the time of large-scale disaster. City Planning Review, 64(6), pp. 64-67, 2018. (In Japanese.)

[7] Rowan, K., Botan, C.H., Kreps, G.L., Samoilenko, S. \& Farnsworth, K., Risk communication education for local emergency managers: Using the CAUSE model for research, education, and outreach. Handbook of Risk and Crisis Communication, eds R.L. Heath \& H.D. O’Hair, Taylor and Francis: London, pp. 168-191, 2009.

[8] Suzuki, T., Wisdom, Technique, Mechanism to Protect Life from Great Disaster, Shizuoka Academic Publishing: Shizuoka, pp. 154-196, 2014. (In Japanese.)

[9] Suzuki, T., Watanabe, T. \& Okuyama, S., Community disaster management plan to implement extensive evacuation without a single victim against flooding. Journal of Community Disaster Management Society (C-Bosai), 13, pp. 35-50, 2018. (In Japanese.) 